\title{
SCANDINAVIAN JOURNAL OF MEDICINE \& SCIENCE IN SPORTS
}

\section{Age-related differences in vastus lateralis fascicle behavior during fast accelerative leg-extension movements}

\begin{tabular}{|r|l|}
\hline Journal: & Scandinavian Journal of Medicine and Science in Sports \\
\hline Manuscript ID & SJMSS-O-1165-19.R2 \\
\hline Manuscript Type: & Original Article \\
\hline Aute Submitted by the & n/a \\
\hline Complete List of Authors: & $\begin{array}{l}\text { Van Roie, Evelien; KU Leuven, Department of Movement Sciences } \\
\text { Van Driessche, Stijn; KU Leuven, Department of Movement Sciences } \\
\text { Delecluse, Christophe; KU Leuven, Department of Movement Sciences } \\
\text { Vanwanseele, Benedicte; KU Leuven, Department of Movement Sciences }\end{array}$ \\
\hline Keywords: & $\begin{array}{l}\text { explosive strength, force-velocity relationship, fascicle shortening } \\
\text { velocity, knee extensors, rate of power development }\end{array}$ \\
\hline &
\end{tabular}

\section{SCHOLARONE \\ Manuscripts}




\section{Age-related differences in vastus lateralis fascicle behavior during fast accelerative leg-extension movements}

2

3

4

5

6

\section{Evelien Van Roie ${ }^{1 *}$, Stijn Van Driessche ${ }^{1 *}$, Christophe Delecluse ${ }^{1}$, Benedicte Vanwanseele ${ }^{2}$}

${ }^{1}$ KU Leuven, Department of Movement Sciences, Physical Activity, Sports and Health Research Group,

Belgium;

${ }^{2}$ KU Leuven, Department of Movement Sciences, Human Movement Biomechanics Research Group, Belgium.

*equal contribution to the manuscript

\section{Corresponding author:}

Evelien Van Roie

Physical Activity, Sports and Health Research Group

Department of Movement Sciences

Faculty of Movement and Rehabilitation Sciences

KU Leuven

Address: Tervuursevest 101, 3001 Leuven (Belgium)

Telephone: 003216379431

E-mail: evelien.vanroie@kuleuven.be

\section{Acknowledgments}

Evelien Van Roie holds a senior postdoctoral fellowship (12Z5720N) funded by the Research Foundation - Flanders (FWO - Vlaanderen). 


\section{6 \\ ABSTRACT}

3

Leg-extensor rate of power development (RPD) decreases during aging. This study aimed to identify the underlying mechanism of the age-related decline in RPD during a fast acceleration in terms of in vivo vastus lateralis (VL) fascicle shortening behavior. Thirty-nine men aged between 25-69 years performed three maximal isokinetic leg-extensor tests with a fixed initial acceleration of $45^{\circ}$ knee extension in $150 \mathrm{~ms}$ until $340^{\circ} / \mathrm{s}$ knee angular velocity. RPD, VL activity and ultrasound images were recorded to assess (relative) fascicle shortening and mean shortening velocity for the phases of electromechanical delay, pretension and acceleration. Our findings show that fascicle shortening and mean shortening velocity during a fast action increase with aging $(0.002$ per year, $p=0.035$ and 0.005 $\mathrm{s}^{-1}$ per year, $\mathrm{p}=0.097$ respectively), mainly due to a higher amount of shortening in the phase of electromechanical delay. The ratio of VL fascicle length over upper leg length at rest showed a negative correlation $(r=-0.46, p=0.004)$ with $\mathrm{RPD} /$ body mass, while pennation angle at rest showed a trend towards a positive correlation $(\mathrm{r}=0.28, \mathrm{p}=0.089)$. To conclude, our findings indicate that the ability to reach high VL fascicle shortening velocities in vivo is not reduced in older men while performing preprogrammed fast accelerations. The greater amount of fascicle shortening in old age is probably the result of age-related differences in the tendinous properties of the muscle-tendon complex, forcing the fascicles to shorten more in order to transmit the muscle force to the segment.

\section{KEYWORDS}

5 explosive strength, force-velocity relationship, fascicle shortening velocity, knee extensors, rate of power development 


\section{INTRODUCTION}

Impaired maximal leg-extensor strength is an important delimiter of functional capacity at older age, which can lead to increased fall incidence ${ }^{1}$. In addition, to prevent falling, muscle strength should also be developed extremely fast $(<200 \mathrm{~ms})^{2}$ and at a certain movement velocity, resulting in power production. Fast dynamic muscle actions can be represented by the rate of power development (RPD). Recently, we showed that RPD of the leg extensors is decreased during aging and significantly more at high accelerations compared to lower accelerations ${ }^{3}$. In order to counteract these age-related deteriorations in muscle function, a better understanding of the physiological mechanisms behind the age-related decline in RPD at fast accelerations is warranted.

Muscle force generation is influenced by many factors. In particular, rapid force production is influenced by motor unit recruitment and discharge rate, next to muscle fiber type composition ${ }^{4}$. In addition, the larger decline in leg-extensor RPD with aging at higher compared to lower accelerations is accompanied by a reduction in neural drive ${ }^{3}$. At fiber level, it is well known that the length and shortening velocity of muscle fibers have a predominant influence on the magnitude of maximal force production ${ }^{5}$. For in vitro muscle fibers, the force-velocity relationship shows that the higher the shortening velocity is, the lower the force output at that given velocity ${ }^{6}$. Maximal shortening velocity of in vitro muscle fibers has been shown to decline because of age ${ }^{7}$. This causes a leftward shift in the force-velocity relationship, which in turn results in lower force production at high shortening velocities. However, to the authors' knowledge, the effect of aging on in vivo fiber shortening velocity of the leg extensors during fast actions has not yet been investigated.

As an alternative, many studies have focused on whole muscle force-velocity characteristics in aging research ${ }^{8}$. Similar to the in vitro fiber level, knee-extensor muscle strength and maximal contraction velocity have been reported to be reduced during maximal dynamic contractions, inducing a shift in the force-velocity relationship during aging ${ }^{9}$. Moreover, whole muscle maximal contraction velocity has been shown to decline significantly during aging ${ }^{10}$ and was suggested to be a key component in the onset of functional difficulties in the elderly ${ }^{11,12}$. However, these findings may not be representative for in vivo human muscle fibers ${ }^{13}$. In vivo human muscle fiber shortening velocity depends on fiber 
geometry, muscle force and compliance of the series elastic components ${ }^{14}$. Regarding the leg extensors, previous findings represent whole vastus lateralis (VL) muscle-tendon unit (MTU) shortening velocity, which is linearly related to knee joint angular velocity ${ }^{15}$. In particular, the shortening velocity of the MTU has been shown to respond differently to changes in joint angular velocity compared to the fascicles ${ }^{16,17}$. Yet, the effect of aging on in vivo VL fascicle shortening velocity during fast actions remains elusive.

Therefore, this cross-sectional study investigated the age-related differences on in vivo VL fascicle shortening behavior and its relation with RPD in multi-joint leg-extensor tests. We hypothesized that fascicle shortening velocity during fast actions is lower in older versus younger adults and is related to RPD.

\section{MATERIALS AND METHODS}

\subsection{Subjects}

Forty-nine men aged between 20 and 70 years ( $\sim$ ten per decade) were recruited through advertisements and oral communications ${ }^{3}$. Subjects completed a short medical history and physical activity questionnaire and were excluded in case of a cardiovascular disease or acute thrombosis, recent surgery, neuromuscular disease, infection or fever, diabetes and systematic participation in strength or endurance training (i.e. progressive increases in volume and/or intensity) in the prior 6 months. Occasional engagement in physical activity, such as cycling, walking and running was allowed. After thorough examination of power output, electromyography (EMG) signals and ultrasound images and after exclusion of incomplete test samples because of measurement failure of one or more measurements, complete data of thirty-nine healthy subjects aged between 25 and 69 years were used for further analyses. All subjects provided written informed consent. The study was approved by the Medical Ethics Committee UZ KU Leuven / Research in accordance with the declaration of Helsinki.

\subsection{Power measurements}

Power measurements and signal analysis procedures have been previously described ${ }^{3}$. Briefly, an isokinetic leg press machine was developed to measure multi-joint neuromuscular function of the leg 
101 extensors at a sampling frequency of $1000 \mathrm{~Hz}$. The seat and lever arm were adjustable to allow for 102 standardized range of motion (i.e. knee joint angle of $90^{\circ}$ to $160^{\circ}$ and hip joint angle of $70^{\circ}$ to $115^{\circ}$ ). 103 Measurements were performed unilaterally on the right side. The right foot was fully supported and 104 fixed to the foot plate using a solid strap with the lateral malleolus aligned with the point of force 105 application, provoking a heel thrust to minimize the influence of lower-leg muscles and ankle 106 movement. Movement of the lever arm was initiated by surpassing a cut-off torque of $20 \%$ of maximal 107 isometric single-joint strength inducing a low-level of pretension (i.e. 20-70Nm) as previously 108 recommended ${ }^{18}$. This single-joint strength test was performed on a Biodex Medical System 3 109 dynamometer prior to the multi-joint test. Subjects performed four maximal isometric voluntary 110 contractions of the knee extensors at $90^{\circ}$ knee joint angle. They were instructed to push as hard as 111 possible for 5 seconds, separated by a 20 -second rest period ${ }^{19}$. Isometric peak torque was used to set 112 the level of pretension in the multi-joint test.

113 Subjects performed two test sessions separated by a rest day to avoid fatigue. In the first session, 114 familiarization with the protocol was performed. The second session was performed at the same time of 115 day. Participants started with a warming-up on a cycle ergometer at a self-determined submaximal 116 resistance for 10 minutes. For the leg-extensor test, lever arm angular acceleration was preprogrammed 117 using a real-time control program (Simulink, The Mathworks Inc., Natick, United States) at a high 118 acceleration of $3200^{\circ} / \mathrm{s}^{2}$ until an isokinetic lever arm velocity of $540^{\circ} / \mathrm{s}$ was reached. This lever arm angular acceleration corresponds to an extension of $45^{\circ}$ in the knee in $150 \mathrm{~ms}$ until an isokinetic knee angular velocity of $340^{\circ} / \mathrm{s}$ is reached. The test was performed three times with a 30 -second rest period in between. The subjects were clearly instructed to push as fast and as hard as possible.

\subsection{Electromyographic activity}

EMG activity of vastus lateralis (VL) was collected during the multi-joint leg-extensor tests according to previous procedures ${ }^{3}$. Surface electrodes were positioned following the European Recommendations for Surface Electromyography (SENIAM) after careful preparation of the skin (i.e. shaving and cleaning

126 with alcohol) to keep skin impedance low. EMG signals were recorded using wireless EMG electrodes

127 (KINE®, KINE Ltd., Hafnarfjördur, Iceland) with an input impedance of $10 \mathrm{G} \Omega$, a common mode 
128 rejection ratio of $110 \mathrm{~dB}$, a signal-to-noise ratio of $60 \mathrm{~dB}$, a differential detection mode and a built in $\mathrm{A} / \mathrm{D}$

129 converter of $10 \mathrm{bit}$ with a range of $4 \mathrm{mV}$, resulting in a sensitivity of $4 \mu \mathrm{V}$. EMG signals were sampled at $1301600 \mathrm{~Hz}$. An extra electrode unit was used to catch a trigger pulse from the real-time control program at 131 the start of the leg-extensor test to enable synchronization of the EMG signals and the power output. Onset of activation was determined as $>3$ SD of the baseline signal ${ }^{20}$ (Figure 1).

\subsection{Ultrasound measurements}

135 B-mode ultrasound images of VL muscle were obtained at $60 \mathrm{~Hz}$ using a Telemed Echoblaster 128 136 CEXT system (UAB Telemed, Vilnius, Lithuania). A 128-element linear transducer (LV 7.5/60/128Z-

2, UAB Telemed, Vilnius, Lithuania) with a $60 \mathrm{~mm}$ field of view was used at $8 \mathrm{MHz}$. The ultrasound probe was securely fixed to the skin on the lateral mid-thigh of the right leg (i.e. $50 \%$ of the distance between the lateral femoral condyle and the trochanter major) using a semi-flexible holder, elastic

140 bandage and wrapping tape. The probe was oriented in a way to get the best image quality and as parallel 141 as possible to the deep aponeurosis (Figure 2). The start of the ultrasound recordings was used as a 142 trigger pulse and sent to the real-time control program to allow synchronization with EMG and power output (Figure 1).

\section{*FIGURE 2*}

\subsection{Signal processing}

146 All signals were processed off-line using a commercial software package (Matlab R2016b, The 147 MathWorks Inc., Natick, United States). Torque signals were filtered using a fourth-order low-pass 148 Butterworth filter with a $20 \mathrm{~Hz}$ cut-off frequency. Instantaneous power (watt) was calculated as the 149 product of torque $(\mathrm{Nm})$ and velocity $(\mathrm{rad} / \mathrm{s})$. Peak torque $(\mathrm{Nm})$ and peak power (watt) were defined as 150 the highest value of the torque-time and power-time curve, respectively, during the acceleration phase 151 (i.e. from the start of the movement, determined as the point where the cut-off torque was reached, until 152 the isokinetic velocity was reached). The rate of power development (RPD, watt/s) was calculated as 153 the linear slope of the power-time curve during the acceleration phase. Reliability of RPD in our lab was

154 excellent (ICC: .96; SEM(\%): 7.3). 
155 The ultrasound images were processed by tracking three lines representing the superficial 156 aponeurosis, the deep aponeurosis and the orientation of the muscle fascicles with a semi157 automated algorithm ${ }^{21}$. We linearly extrapolated these lines and calculated fascicle length as 158 the distance between the two aponeuroses parallel to the muscle fascicles and the pennation 159 angle as the angle between the muscle fascicles and the deep aponeurosis ${ }^{22}$. This method for 160 estimating fascicle length when the whole fascicle is not visible has been used and validated in 161 a number of studies ${ }^{23-25}$. All data were anonymized to avoid bias within and between individuals. The ultrasound data was filtered using a $4^{\text {th }}$ order low-pass Butterworth filter with a cut-off frequency of $16310 \mathrm{~Hz}$. Fascicle length $(\mathrm{mm})$ and pennation angle $\left({ }^{\circ}\right)$ at rest in the starting position of the leg-extensor 164 test (i.e. knee joint angle of $90^{\circ}$ and hip joint angle of $70^{\circ}$ ) were analyzed. In addition, relative fascicle 165 length was calculated by dividing it by upper leg length, measured as the distance between the lateral 166 femoral condyle and the trochanter major.

167 Fascicle lengths during the leg-extensor test were normalized to the fascicle length at rest in the starting 168 position of the test. Fascicle shortening was calculated as the difference between minimum and maximum fascicle length in the different phases: (1) from the onset of VL activation till the start of 170 torque production (i.e. phase of electromechanical delay - P1), (2) from the start of torque production 171 till the moment the cutoff torque was reached (i.e. phase of pretension - P2), (3) from the moment the 172 cutoff torque was reached till the end of the acceleration phase (i.e. acceleration phase - P3) and (4) 173 from the onset of VL activation till the end of the acceleration phase (i.e. complete test) (Figure 1). 174 Fascicle shortening velocity $\left(\mathrm{s}^{-1}\right)$ was calculated at the first derivative of the fascicle length to the 175 time. Mean shortening velocity $\left(\mathrm{s}^{-1}\right)$ was calculated over the different time phases. The error in the 176 estimation of fascicle length using this method has been reported to be $2 \%-7 \%{ }^{26}$. We tested our intra177 rater reliability of the ultrasound processing by non-consecutively tracking the same images twice for 178 six older subjects (ICC: .96 - .98; SEM(\%): 4.9 - 7.9). For all data, the mean of the three trials was used 179 for further analyses. 


\subsection{Statistical analyses}

181 All statistical analyses were performed using R software, version 1.0.153. Descriptive statistics were 182 represented as means and standard deviations. For this purpose only, subjects were divided in three age 183 categories (25-40 years, 40-55 years, 55-70 years). To study the effect of age on fascicle length and 184 pennation angle at rest, fascicle shortening and mean shortening velocity (of the complete tests and the three different phases separately), we built linear models using the function $1 \mathrm{~m}$. Age was entered as fixed 186 effect into the model and was used as continuous variable. Statistical significance was set at $\mathrm{p}<0.05$ for 187 all analyses.

188 Pearson's correlation coefficients were calculated to examine the association of fascicle length and 189 pennation angle at rest, fascicle shortening and mean shortening velocity with RPD normalized to body 190 mass.

Descriptive statistics are presented in Table 1. The RPD value of one subject (age 53.9 years) was deleted in the analyses, as he was considered an outlier (defined as a value lower than the lowest quartile minus 1.5 times the interquartile range).

196 At rest, absolute VL fascicle length and fascicle length relative to the upper leg length was significantly 197 higher in older adults (increase of $0.80 \mathrm{~mm}$ per year, $\mathrm{p}=0.025$ and 0.002 per year, $\mathrm{p}=0.005$ 198 respectively), while pennation angle at rest was significantly lower (decrease of $-0.07^{\circ}$ per year, $\mathrm{p}=$ 199 0.002).

200 For the complete test from the onset of VL activation till the end of the acceleration phase, more VL 201 fascicle shortening, i.e. about $0.002 \mathrm{~mm} / \mathrm{mm}$ per year $(\mathrm{p}=0.035)$, was shown in older adults. Similarly, 202 mean shortening velocity was higher in older adults (increase of $0.005 \mathrm{~s}^{-1}$ per year, $\mathrm{p}=0.097$ ) (Figure $2033 \mathrm{~A}$ and $3 \mathrm{~B})$.

204 Subdivision of the complete test in successive phases of electromechanical delay (P1), pretension (P2) 205 and acceleration (P3) revealed more fascicle shortening in older adults in P1, i.e. an increase of on 
average 0.002 per year $(p=0.043)$, but not in $\mathrm{P} 2$ and $\mathrm{P} 3(\mathrm{p}=0.853$ and $\mathrm{p}=0.592)$. Furthermore, mean shortening velocity did not differ with age in either P1 $(p=0.478), P 2(p=0.324)$ or P3 $(p=0.616)$.

\section{*FIGURE $3 *$}

In relation to RPD/body mass, VL fascicle length and the relative fascicle length to upper leg length at rest showed a negative correlation $(r=-0.36, p=0.026$ and $r=-0.46, p=0.004)$, while pennation angle at rest showed a trend towards a positive correlation $(\mathrm{r}=0.28, \mathrm{p}=0.089)$ (Figure 4). However, correlation coefficients between normalized RPD and VL fascicle shortening $(r=0.14, p=0.391)$ or mean shortening velocity $(r=0.055, \mathrm{p}=0.743)$ over the complete test was not significant.

\section{*FIGURE 4*}

\section{DISCUSSION}

This study aimed at identifying the underlying mechanisms of age-related differences in leg-extensor RPD in response to fast accelerative actions in terms of VL fascicle shortening behavior. Our findings provide experimental evidence that in vivo fascicle shortening and shortening velocity during fast actions are higher in older adults compared to younger adults, mainly due to a higher amount of shortening in the phase of electromechanical delay. This higher amount of shortening at older age coincides with longer VL fascicle lengths and smaller pennation angles at rest. Moreover, both fascicle length and pennation angle are associated with RPD, while fascicle shortening velocity is not related to RPD

In contrast with our first hypothesis, in vivo VL fascicle shortening velocity is higher in older versus younger adults when performing fast actions. Although this might seem to contradict the age-related decline in maximal contraction velocity at the in vitro fiber level ${ }^{7}$, one should realize that a condition of unloaded shortening does not exist during in vivo leg-extension movements. Our test was not unloaded, considering that a pre-load of $20 \%$ of the isometric maximal strength was used to ensure a limited amount of pretension of the muscles before the start of the movement. Peak torques developed during the subsequent acceleration phase were up to $55 \%$ of peak torques at slow isokinetic velocity (data not shown). To conclude, the ability to produce force at fixed high accelerations is not necessarily related to in vitro maximal contraction velocity of fibers. In addition to the muscle fibers, we have 
233 measured the muscle fascicles in a muscle-tendon complex where the tendon plays an important role in

234 the rate of force development ${ }^{4}$.

235 Similarly, it is difficult to compare our data to previous findings on whole muscle level ${ }^{11,27}$, as we used 236 an approach in which accelerations were controlled instead of torque production (i.e. an isotonic 237 approach). This approach with preprogrammed acceleration was chosen to ensure a fast and challenging 238 movement in all individuals, as older adults might be limited to produce such high velocities in voluntary 239 isotonic actions ${ }^{12}$. Isotonic approaches did show a reduction in contraction velocity of the whole leg240 extensor muscles with aging ${ }^{11,27}$. Whether this coincides with a reduced fascicle shortening velocity 241 remains to be investigated in isotonic set-ups. Of note, studies have shown that the muscle-tendon unit 242 response can differ from VL fascicle shortening behavior during concentric knee-extension movements $243 \quad 17,28$.

244 The higher fascicle shortening velocity combined with a greater amount of fascicle shortening at older 245 age is related to age-related differences in muscle architecture properties such as VL fascicle length and 246 pennation angle at rest. In agreement with previous research, VL pennation angle was greater in young 247 than in older men ${ }^{29-31}$. In addition, VL fascicles were longer in older versus younger men, even after 248 correction for upper leg length, although positioning (and corresponding joint angles) of subjects was 249 identical. Previous findings regarding age-related differences in vastus lateralis fascicle length are 250 inconsistent, with reports showing either no difference in absolute ${ }^{30}$ or relative fascicle length (to limb 251 length) between younger and older men ${ }^{29,32}$ and young and older women ${ }^{33}$, longer relative fascicle 252 lengths in older women compared to young ${ }^{29}$ or longer absolute fascicle length in young compared to 253 older adults ${ }^{31,34}$.

254 The greater amount of fascicle shortening is not fully explained by greater starting lengths at rest, given 255 that relative fascicle shortening was significantly greater in older adults, more specifically in the phase 256 of electromechanical delay (P1). The similar amount of fascicle shortening during the pretension (P2) 257 and acceleration phase (P3) in young and older adults suggests that the fascicles of older adults can act 258 similarly to those of younger adults as soon as the electromechanical preparation phase is finished. The 259 greater fascicle shortening at older age during P1 coincided with an increase in the duration of the phase 260 of electromechanical delay, although this increase was not significant. The phase of electromechanical 
261 delay has previously been observed to be prolonged and this was accompanied by an increase in 262 compliance of the patellar tendon in older individuals ${ }^{35}$. During this electromechanical delay phase, 263 slack in the muscle and tendon is taken up. Therefore, tendon slack will influence the duration and 264 amount of shortening in the fascicle during this phase. Our results indicate that in older adults more 265 slack needs to be taken up. Although data on tendon slack in an ageing population is still lacking, 266 multiple reports consistently demonstrated decreases in tendon stiffness with advancing age ${ }^{32,36}$. The 267 underlying mechanisms of this age-related difference are not yet fully understood, but might be linked 268 to changes in tendon dimensions, hydration status, glycosamine concentration, elastin content, cross269 linking or collagen content contribute ${ }^{37,38}$. Taken together, the higher compliance and potentially slack 270 length of the tendon at older age could have forced the fascicles to shorten more in order to transmit the 271 muscle force to the segment.

272 In previous research, the stiffness of VL tendon-aponeurosis complex was positively related to isometric 273 knee-extensor rate of torque development and maximal vertical jump performance in healthy 274 competitive volleyball players and cyclists ${ }^{39}$. In addition, reduced tendon stiffness has been suggested 275 to contribute to the reduced rate of torque development in healthy older men ${ }^{37}$. However, in the current 276 study, we did not observe a significant relationship between fascicle shortening and RPD, although more 277 fascicle shortening at old age as a consequence of reduced tendon properties can result in fascicle lengths 278 that are less optimal for force production based on the force-length relationship of skeletal muscles ${ }^{40}$. 279 RPD was negatively related to normalized fascicle length and positively related to pennation angle at 280 rest. The effect of muscle architecture on rapid force production is currently poorly understood (for a 281 review, see Maffiuletti et al. ${ }^{4}$ ). More pennation allows for a greater muscle cross-sectional area for a 282 given muscle volume and therefore greater absolute rate of force rise ${ }^{4}$. Theoretically, muscles with 283 longer fascicles have an increased shortening velocity potential, but could also exhibit a slower force 284 rise because of a greater tendon compliance ${ }^{4,41}$. Taken together, our results seem to indicate that RPD at 285 fixed high accelerations is more influenced by tissue compliance and pennation angle than by the fibers' 286 shortening velocity potential. Other factors that may negatively influence the ability to rapidly produce 287 force and power at old age, are decreased neural excitation rate ${ }^{3,42}$, greater shortening-induced torque 
288 depression $^{43}$, decreased potential to use variable gearing in the muscle ${ }^{44}$ and changes in muscle size and 289 fiber properties ${ }^{4,45,46}$.

290 The following limitations should be kept in mind when interpreting our findings. First, age-related 291 changes were based on cross-sectional findings, which may be confounded by inter-individual 292 differences and may be divergent from longitudinal findings. Next, fascicle shortening was analyzed in 293 the VL only, whereas other muscles contribute to leg-extensor movements. Furthermore, although some 294 muscle deformation may only be visible in 3D, fascicle measurements were based on two-dimensional 295 ultrasound images. For the analysis, it was assumed that fascicles are represented by straight lines, 296 although it has been shown that this may result in an underestimation of absolute lengths of $2-7 \%{ }^{26}$. 297 However, absolute length differences between groups are not the main focus of this study. The main 298 findings are based on length changes (shortening and velocity), which according to Brennan et al. ${ }^{47}$ are 299 not largely affected by the straight-line interpolation. Image quality can vary with age and can also 300 influence the reliability of the data analysis. We carefully checked the quality of the images and also 301 performed our reliability test on the older age group. The used ultrasound sampling frequency of $60 \mathrm{~Hz}$ 302 might have been relative low to investigate fast accelerations. However, the total duration of the leg 303 extensor test is approximately $370 \mathrm{~ms}$ and the average time of the acceleration and electromechanical 304 delay phase is approximately $150 \mathrm{~ms}$. This means that on average 21 images for the whole test and 9 305 images per phase were analyzed. In addition, good reliability of the method was shown and our fascicle 306 shortening velocities are very similar to those reached during isolated high velocities knee extensions 307 using ultrafast ultrasound ${ }^{28}$.

\section{PERSPECTIVES}

309 Our findings indicate that the ability to reach high VL fascicle shortening velocities in vivo is not

310 reduced in older men while performing preprogrammed fast accelerations. The greater amount of 311 fascicle shortening in old age is probably the result of reduced stiffness of the patellar tendon, forcing 312 the fascicles to shorten more in order to transmit the muscle force to the segment. Taken together, the 313 rate of power development at fixed high accelerations seems more influenced by tendon compliance 
314 than by the fibers' intrinsic capacity to shorten fast. Exercise programs in older adults should therefore

315 also target improvements in stiffness of the muscle-tendon unit.

\section{CONFLICTS OF INTEREST}

317 The authors declare that they have no conflict of interest.

\section{REFERENCES}

319 1. Pijnappels M, van der Burg JCE, Reeves ND, van Dieën JH. Identification of elderly fallers by 320 muscle strength measures. European Journal of Applied Physiology. 2008;102(5):585-592.

3212 2. Pijnappels M, Bobbert MF, van Dieën JH. Control of support limb muscles in recovery after 322 tripping in young and older subjects. Exp Brain Res. 2005;160(3):326-333.

323 3. Van Driessche S, Van Roie E, Vanwanseele B, Delecluse C. Effect of acceleration on the rate 324 of power development and neural activity of the leg extensors across the adult life span. Eur J Appl 325 Physiol. 2019;119(3):781-789.

326 4. Maffiuletti NA, Aagaard P, Blazevich AJ, Folland J, Tillin N, Duchateau J. Rate of force 327 development: physiological and methodological considerations. Eur J Appl Physiol. 2016;116(6):10913281116.

329 5. Hill AV. The heat of shortening and the dynamic constants of muscle. Proceedings of the Royal 330 Society of London Series B - Biological Sciences. 1938;126(843):136-195.

331 6. Bottinelli R, Pellegrino MA, Canepari M, Rossi R, Reggiani C. Specific contributions of various 332 muscle fibre types to human muscle performance: an in vitro study. Journal of electromyography and 333 kinesiology : official journal of the International Society of Electrophysiological Kinesiology. $334 \quad 1999 ; 9(2): 87-95$.

335 7. D'Antona G, Pellegrino MA, Adami R, et al. The effect of ageing and immobilization on 336 structure and function of human skeletal muscle fibres. The Journal of physiology. 2003;552(Pt 2):499337511.

338 8. Raj IS, Bird SR, Shield AJ. Aging and the force-velocity relationship of muscles. Experimental 339 Gerontology. 2010;45(2):81-90. 
3409 9. Petrella JK, Kim JS, Tuggle SC, Hall SR, Bamman MM. Age differences in knee extension 341 power, contractile velocity, and fatigability. J Appl Physiol (1985). 2005;98(1):211-220.

342 10. Lanza IR, Towse TF, Caldwell GE, Wigmore DM, Kent-Braun JA. Effects of age on human 343 muscle torque, velocity, and power in two muscle groups. J Appl Physiol (1985). 2003;95(6):2361-2369. 344 11. Pojednic RM, Clark DJ, Patten C, Reid K, Phillips EM, Fielding RA. The specific contributions 345 of force and velocity to muscle power in older adults. Exp Gerontol. 2012;47(8):608-613.

346 12. Van Roie E, Verschueren SM, Boonen S, et al. Force-velocity characteristics of the knee 347 extensors: an indication of the risk for physical frailty in elderly women. Arch Phys Med Rehabil. $348 \quad 2011 ; 92(11): 1827-1832$.

349 13. Kawakami Y, Fukunaga T. New insights into in vivo human skeletal muscle function. Exercise 350 and sport sciences reviews. 2006;34(1):16-21.

351 14. Cronin NJ, Lichtwark G. The use of ultrasound to study muscle-tendon function in human 352 posture and locomotion. Gait \& Posture. 2013;37(3):305-312.

353 15. Hawkins D, Hull ML. A method for determining lower extremity muscle-tendon lengths during 354 flexion/extension movements. Journal of Biomechanics. 1990;23(5):487-494.

355 16. Ichinose Y, Kawakami Y, Ito M, Kanehisa H, Fukunaga T. In vivo estimation of contraction 356 velocity of human vastus lateralis muscle during "isokinetic" action. J Appl Physiol. 2000;88(3):851357856.

358 17. Fontana HdB, Roesler H, Herzog W. In vivo vastus lateralis force-velocity relationship at the 359 fascicle and muscle tendon unit level. Journal of electromyography and kinesiology : official journal of 360 the International Society of Electrophysiological Kinesiology. 2014;24(6):934-940.

361 18. Tillin NA, Pain MT, Folland J. Explosive force production during isometric squats correlates 362 with athletic performance in rugby union players. J Sports Sci. 2013;31(1):66-76.

363 19. Van Driessche S, Van Roie E, Vanwanseele B, Van Leemputte M, Delecluse C. Age-related 364 decline in leg-extensor power development in single- versus multi-joint movements. Exp Gerontol. $365 \quad 2018 ; 110: 98-104$. 
366 20. Hodges PW, Bui BH. A comparison of computer-based methods for the determination of onset 367 of muscle contraction using electromyography. Electroencephalogr Clin Neurophysiol. $368 \quad 1996 ; 101(6): 511-519$.

369 21. Farris DJ, Lichtwark GA. UltraTrack: Software for semi-automated tracking of muscle fascicles 370 in sequences of B-mode ultrasound images. Computer Methods and Programs in Biomedicine. $371 \quad 2016 ; 128: 111-118$.

372 22. Aeles J, Lichtwark G, Peeters D, Delecluse C, Jonkers I, Vanwanseele B. Effect of a prehop on 373 the muscle-tendon interaction during vertical jumps. J Appl Physiol. 2018;124(5):1203-1211.

374 23. Blazevich AJ, Cannavan D, Coleman DR, Horne S. Influence of concentric and eccentric 375 resistance training on architectural adaptation in human quadriceps muscles. $J$ Appl Physiol (1985). $376 \quad 2007 ; 103(5): 1565-1575$.

377 24. Massey G, Evangelidis P, Folland J. Influence of contractile force on the architecture and 378 morphology of the quadriceps femoris. Exp Physiol. 2015;100(11):1342-1351.

379 25. Morse CI, Thom JM, Birch KM, Narici MV. Changes in triceps surae muscle architecture with 380 sarcopenia. Acta Physiol Scand. 2005;183(3):291-298.

381 26. Finni T, Ikegawa S, Lepola V, Komi PV. Comparison of force-velocity relationships of vastus 382 lateralis muscle in isokinetic and in stretch-shortening cycle exercises. Acta Physiologica Scandinavica. $383 \quad 2003 ; 177(4): 483-491$.

384 27. Van Roie E, Van Driessche S, Inglis AJ, Thomis M, Delecluse C. Rate of power development 385 of the knee extensors across the adult life span: A cross-sectional study in 1387 Flemish Caucasians. 386 Exp Gerontol. 2018;110:260-266.

387 28. Hauraix H, Dorel S, Rabita G, Guilhem G, Nordez A. Muscle fascicle shortening behaviour of 388 vastus lateralis during a maximal force-velocity test. Eur J Appl Physiol. 2017;117(2):289-299.

389 29. Kubo K, Kanehisa H, Azuma K, et al. Muscle architectural characteristics in young and elderly 390 men and women. Int J Sports Med. 2003;24(2):125-130.

391 30. McPhee JS, Cameron J, Maden-Wilkinson T, et al. The Contributions of Fiber Atrophy, Fiber 392 Loss, In Situ Specific Force, and Voluntary Activation to Weakness in Sarcopenia. J Gerontol A Biol 393 Sci Med Sci. 2018;73(10):1287-1294. 
394 31. Power GA, Makrakos DP, Rice CL, Vandervoort AA. Enhanced force production in old age is 395 not a far stretch: an investigation of residual force enhancement and muscle architecture. Physiol Rep. $396 \quad 2013 ; 1(1): \mathrm{e} 00004$.

397 32. Karamanidis K, Arampatzis A. Mechanical and morphological properties of human quadriceps 398 femoris and triceps surae muscle-tendon unit in relation to aging and running. $J$ Biomech. $3992006 ; 39(3): 406-417$.

400 33. Kubo K, Kanehisa H, Azuma K, et al. Muscle architectural characteristics in women aged 2040179 years. Med Sci Sports Exerc. 2003;35(1):39-44.

402 34. Wu R, Delahunt E, Ditroilo M, Lowery M, De Vito G. Effects of age and sex on neuromuscular403 mechanical determinants of muscle strength. Age (Dordrecht, Netherlands). 2016;38(3):57.

404 35. Reeves ND, Maganaris CN, Narici MV. Effect of strength training on human patella tendon 405 mechanical properties of older individuals. The Journal of physiology. 2003;548(Pt 3):971-981.

406 36. Kubo K, Kanehisa H, Miyatani M, Tachi M, Fukunaga T. Effect of low-load resistance training 407 on the tendon properties in middle-aged and elderly women. Acta Physiologica Scandinavica. $408 \quad 2003 ; 178(1): 25-32$.

409 37. Quinlan JI, Maganaris CN, Franchi MV, et al. Muscle and Tendon Contributions to Reduced 410 Rate of Torque Development in Healthy Older Males. The Journals of Gerontology: Series A. $411 \quad 2018 ; 73(4): 539-545$.

412 38. Narici MV, Maganaris CN. Plasticity of the Muscle-Tendon Complex With Disuse and Aging. 413 Exercise and sport sciences reviews. 2007;35(3):126-134.

414 39. Bojsen-Møller J, Magnusson SP, Rasmussen LR, Kjaer M, Aagaard P. Muscle performance 415 during maximal isometric and dynamic contractions is influenced by the stiffness of the tendinous 416 structures. J Appl Physiol. 2005;99(3):986-994.

417 40. Ichinose Y, Kawakami Y, Ito M, Fukunaga T. Estimation of active force-length characteristics 418 of human vastus lateralis muscle. Acta anatomica. 1997;159(2-3):78-83.

419 41. Blazevich AJ, Cannavan D, Horne S, Coleman DR, Aagaard P. Changes in muscle force-length 420 properties affect the early rise of force in vivo. Muscle \& nerve. 2009;39(4):512-520. 
421 42. Clark DJ, Pojednic RM, Reid KF, et al. Longitudinal decline of neuromuscular activation and 422 power in healthy older adults. J Gerontol A Biol Sci Med Sci. 2013;68(11):1419-1425.

423 43. Power GA, Makrakos DP, Stevens DE, Herzog W, Rice CL, Vandervoort AA. Shortening424 induced torque depression in old men: implications for age-related power loss. Exp Gerontol. $425 \quad 2014 ; 57: 75-80$.

426 44. Holt NC, Danos N, Roberts TJ, Azizi E. Stuck in gear: age-related loss of variable gearing in 427 skeletal muscle. J Exp Biol. 2016;219(Pt 7):998-1003.

428 45. Lexell J, Taylor CC, Sjostrom M. What is the cause of the ageing atrophy? Total number, size 429 and proportion of different fiber types studied in whole vastus lateralis muscle from 15- to 83-year-old 430 men. Journal of the neurological sciences. 1988;84(2-3):275-294.

431 46. Andersen JL, Terzis G, Kryger A. Increase in the degree of coexpression of myosin heavy chain 432 isoforms in skeletal muscle fibers of the very old. Muscle \& nerve. 1999;22(4):449-454.

433 47. Brennan SF, Cresswell AG, Farris DJ, Lichtwark GA. In vivo fascicle length measurements via 434 B-mode ultrasound imaging with single vs dual transducer arrangements. J Biomech. 2017;64:240-244. 435 


\section{TABLES}

TABLE 1 Subject characteristics, leg-extensor rate of power development and vastus lateralis fascicle shortening behavior by age group.

\begin{tabular}{|c|c|c|c|c|}
\hline & & $25-40$ years & $40-55$ years & $55-70$ years \\
\hline & $\mathrm{n}$ & 15 & $12-13$ & 11 \\
\hline & Age (years) & $29.7 \pm 4.6$ & $47.3 \pm 4.5$ & $62.5 \pm 4.9$ \\
\hline \multirow[t]{3}{*}{ Anthropometrics } & Body mass (kg) & $79.8 \pm 12.0$ & $83.8 \pm 10.8$ & $82.0 \pm 13.6$ \\
\hline & Body height (cm) & $180.9 \pm 5.6$ & $181.2 \pm 5.7$ & $174.8 \pm 4.0$ \\
\hline & $\operatorname{BMI}\left(\mathrm{kg} / \mathrm{m}^{2}\right)$ & $24.4 \pm 3.4$ & $25.5 \pm 2.6$ & $26.7 \pm 5.1$ \\
\hline \multirow[t]{4}{*}{ Muscle performance $\dagger$} & Peak torque & $105.5 \pm 20.4$ & $94.1 \pm 23.9$ & $81.0 \pm 16.1$ \\
\hline & Peak power & $996.1 \pm 191.9$ & $884.1 \pm 231.4$ & $754.2 \pm 157.3$ \\
\hline & RPD (watt/s) & $6137 \pm 1245$ & $5700 \pm 1228$ & $4580 \pm 1003$ \\
\hline & RPD/BM (watt/(s.kg)) & $77.2 \pm 11.4$ & $66.4 \pm 11.2$ & $56.2 \pm 10.7$ \\
\hline \multirow[t]{3}{*}{ At rest } & Fascicle length $(\mathrm{mm})$ & $131 \pm 24$ & $139 \pm 30$ & $168 \pm 38$ \\
\hline & Fascicle length (mm) / upper leg length (mm) & $0.30 \pm 0.05$ & $0.32 \pm 0.07$ & $0.37 \pm 0.09$ \\
\hline & Pennation angle $\left(^{\circ}\right)$ & $10.4 \pm 1.6$ & $9.5 \pm 2.2$ & $8.0 \pm 2.3$ \\
\hline \multirow[t]{3}{*}{ Complete test } & Fascicle shortening $(\mathrm{mm} / \mathrm{mm})$ & $-0.34 \pm 0.08$ & $-0.39 \pm 0.07$ & $-0.41 \pm 0.10$ \\
\hline & Mean shortening velocity $\left(\mathrm{s}^{-1}\right)$ & $-0.93 \pm 0.24$ & $-1.06 \pm 0.24$ & $-1.09 \pm 0.23$ \\
\hline & Duration (s) & $0.368 \pm 0.053$ & $0.370 \pm 0.043$ & $0.362 \pm 0.044$ \\
\hline \multirow[t]{2}{*}{ Phase 1 - electromechanical delay } & Fascicle shortening $(\mathrm{mm} / \mathrm{mm})$ & $-0.09 \pm 0.06$ & $-0.10 \pm 0.06$ & $-0.13 \pm 0.09$ \\
\hline & Mean shortening velocity $\left(\mathrm{s}^{-1}\right)$ & $-0.77 \pm 0.55$ & $-0.77 \pm 0.48$ & $-0.96 \pm 0.61$ \\
\hline
\end{tabular}




\begin{tabular}{|c|c|c|c|c|}
\hline & Duration (s) & $0.137 \pm 0.048$ & $0.146 \pm 0.041$ & $0.143 \pm 0.042$ \\
\hline \multirow[t]{3}{*}{ Phase 2 - pretension } & Fascicle shortening $(\mathrm{mm} / \mathrm{mm})$ & $-0.11 \pm 0.05$ & $-0.11 \pm 0.05$ & $-0.11 \pm 0.06$ \\
\hline & Mean shortening velocity $\left(\mathrm{s}^{-1}\right)$ & $-1.23 \pm 0.53$ & $-1.36 \pm 0.64$ & $-1.48 \pm 0.62$ \\
\hline & Duration (s) & $0.090 \pm 0.019$ & $0.085 \pm 0.013$ & $0.076 \pm 0.018$ \\
\hline \multirow[t]{3}{*}{ Phase 3 - acceleration } & Fascicle shortening $(\mathrm{mm} / \mathrm{mm})$ & $-0.13 \pm 0.04$ & $-0.17 \pm 0.04$ & $-0.15 \pm 0.06$ \\
\hline & Mean shortening velocity $\left(\mathrm{s}^{-1}\right)$ & $-0.95 \pm 0.30$ & $-1.22 \pm 0.32$ & $-1.03 \pm 0.42$ \\
\hline & Duration (s) & $0.142 \pm 0.005$ & $0.139 \pm 0.006$ & $0.143 \pm 0.002$ \\
\hline
\end{tabular}

$\mathrm{BMI}=$ body mass index $; \mathrm{BM}=$ body mass RPD $=$ rate of power development

$\dagger$ Muscle performance outcomes represent values from the acceleration phase of the movement 


\section{FIGURE LEGENDS}

FIGURE 1 Representation of torque, power and vastus lateralis (VL) fascicle length and electromyographic activity (EMG) of a random subject. (P1) phase of electromechanical delay, (P2) phase of pretension, (P3) phase of acceleration.

FIGURE 2 Example of the tracking procedure of an ultrasound image of the vastus lateralis. The black broken line represents the superficial aponeurosis (1) and deep aponeurosis (2), and the white broken line the muscle fascicle orientation (3).

FIGURE 3 Age-related increase in vastus lateralis relative fascicle shortening (A) and relative mean fascicle shortening velocity (B) across 39 subjects (aged 25 to 69 years) during the leg-extensor test.

FIGURE 4 Association between the rate of power development (RPD) and relative vastus lateralis fascicle length to upper leg length at rest $(r=-0.46, p=0.004$; A) or pennation angle at rest $(r=0.28, p$ $=0.089 ; \mathrm{B}$ ) across 38 subjects (aged 25 to 69 years) during the leg-extensor test. RPD is normalized to body mass (BM). 

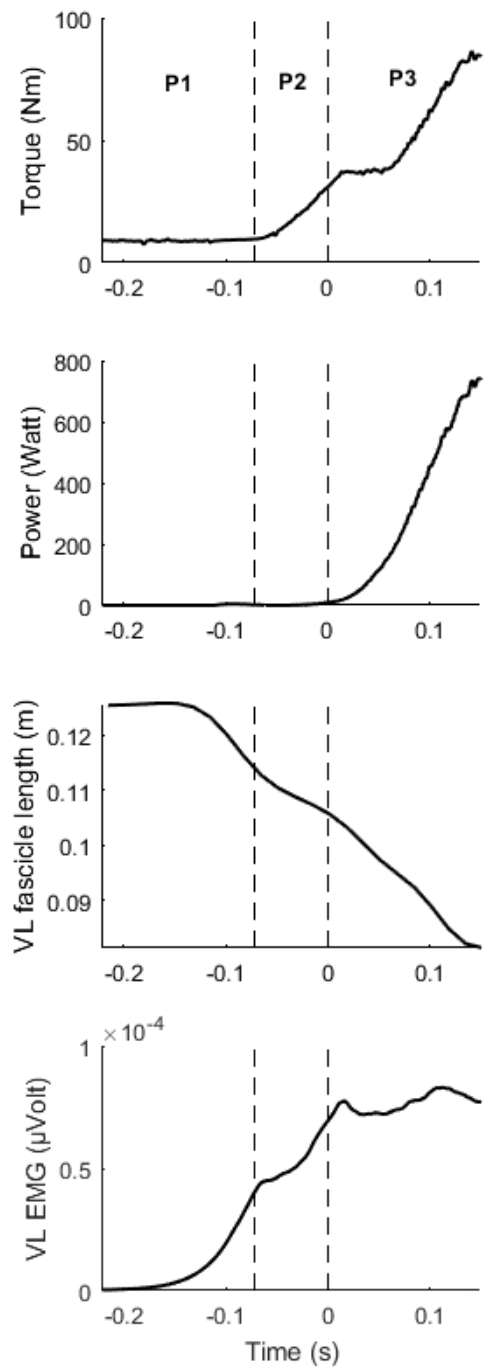

$79 \times 236 \mathrm{~mm}(96 \times 96 \mathrm{DPI})$ 


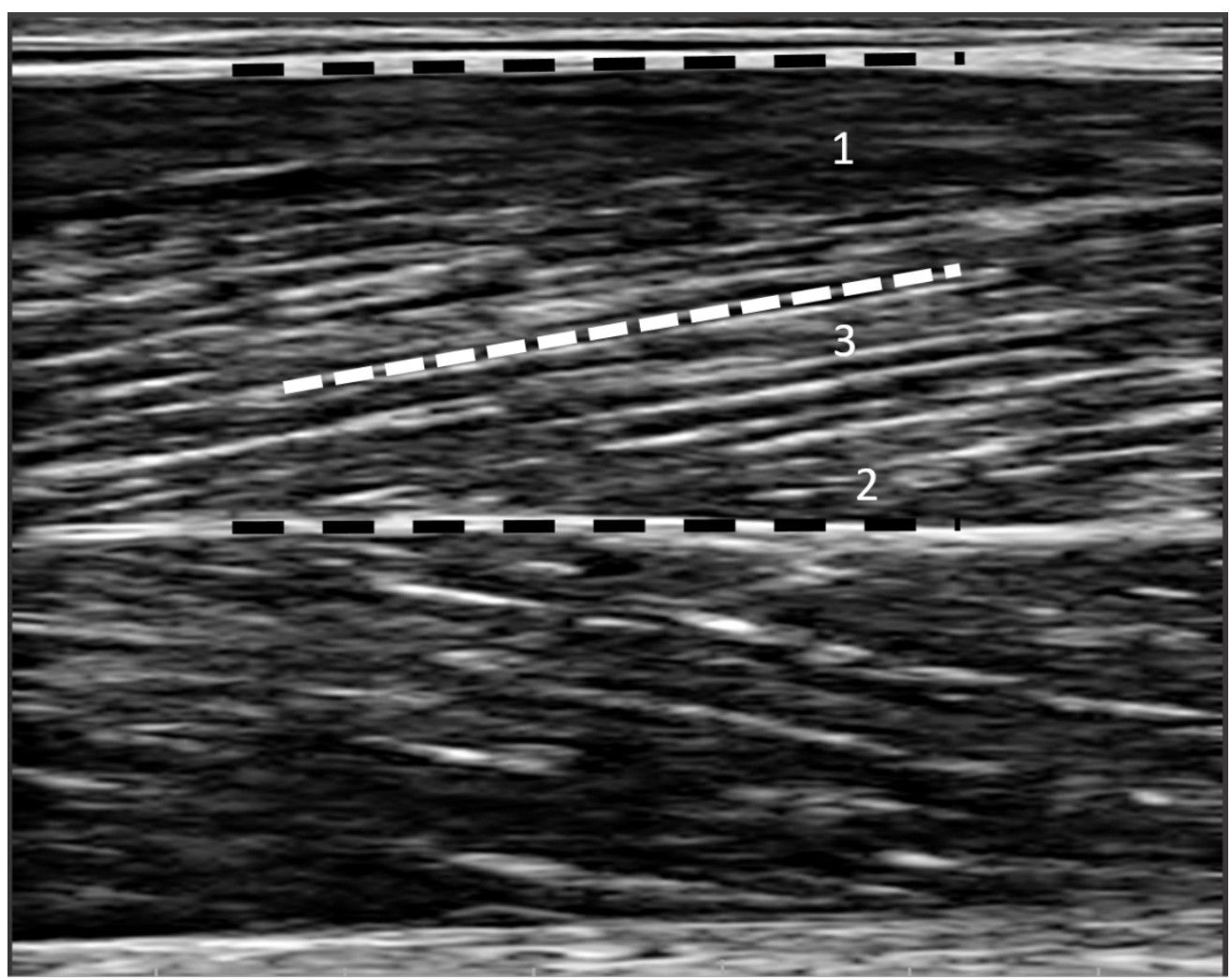

$208 \times 164 m m(150 \times 150$ DPI $)$ 


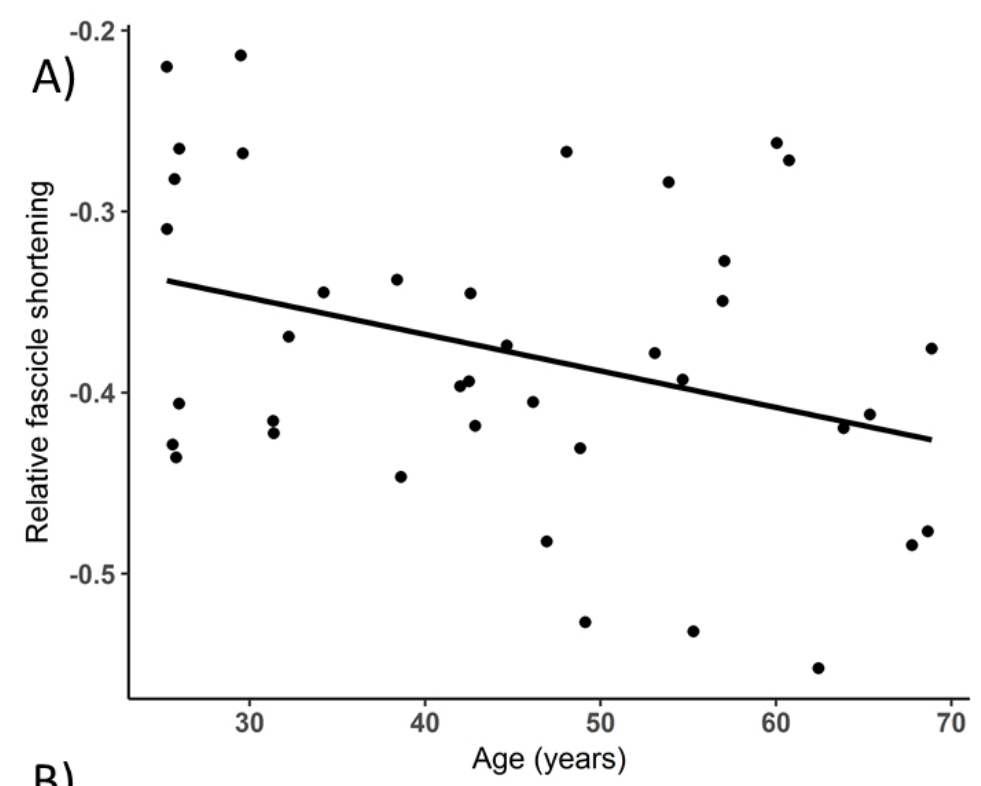

B)

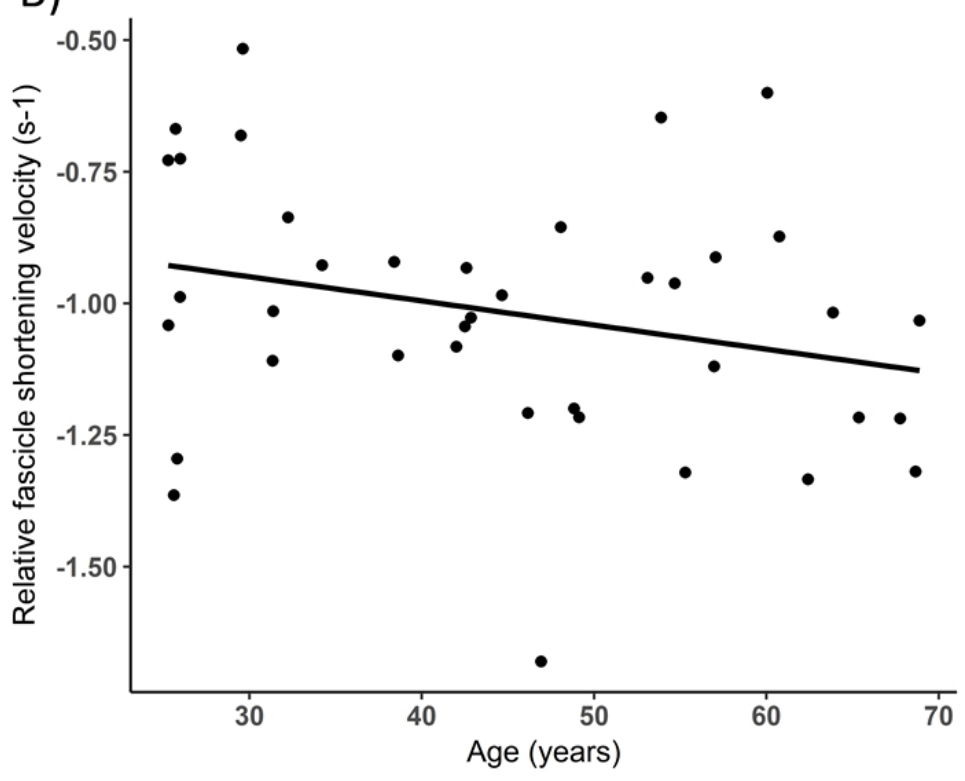

$30 \times 48 \mathrm{~mm}(600 \times 600 \mathrm{DPI})$ 

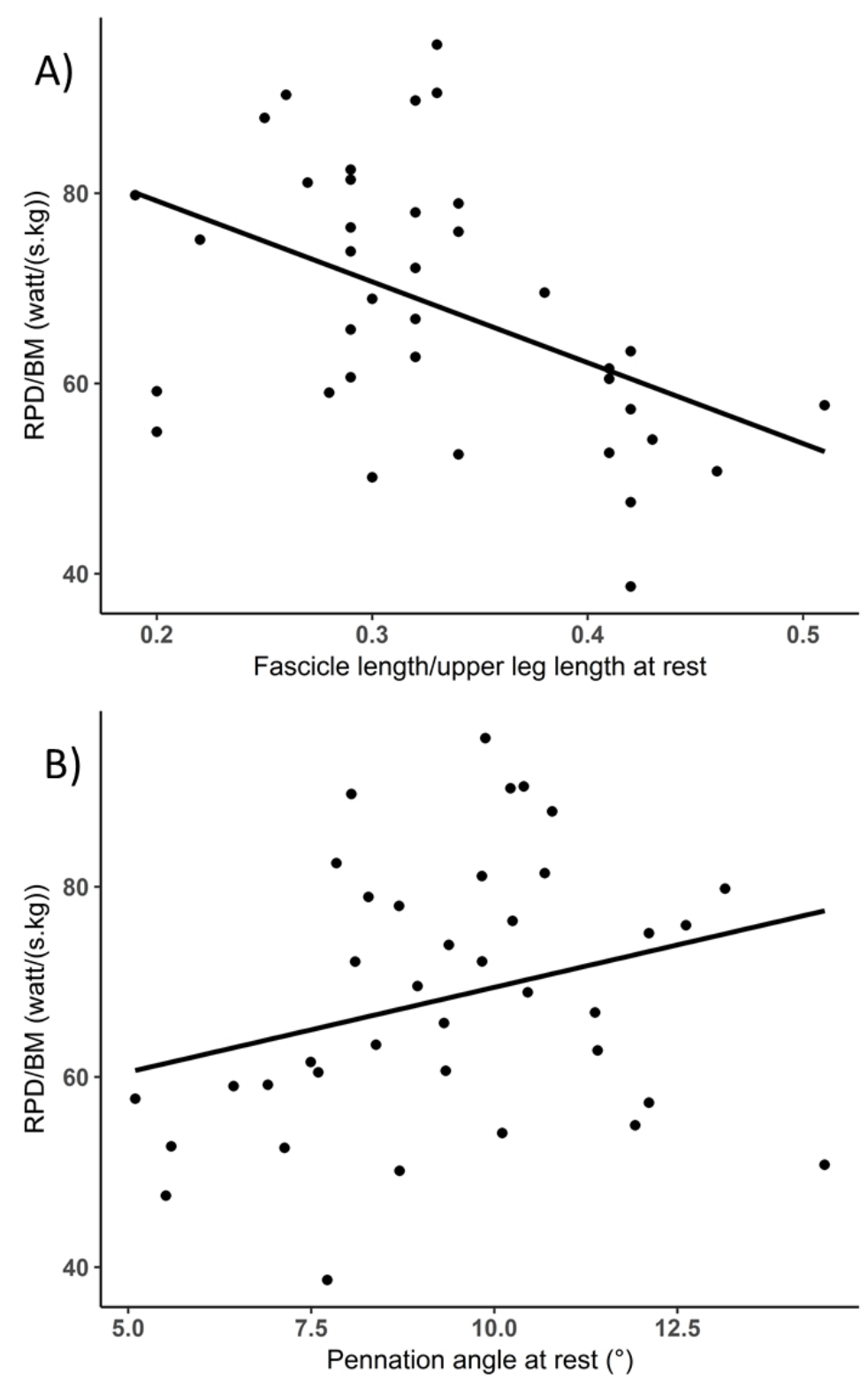

$30 \times 48 \mathrm{~mm}(600 \times 600 \mathrm{DPI})$ 